\title{
Isolation and Characterization of Some Fungi Associated with Superficial Fungal Infections
}

\author{
Sani U. Diso ${ }^{1}$, Ja'afar S. Adam ${ }^{1}$, Lurwan Mu'azu ${ }^{2}$, Muhammad S. Abdallah ${ }^{3}$, Muhammad Ali ${ }^{4^{*}}$ \\ ${ }^{I}$ Department of Pharmaceutical Technology, School of Technology, Kano State Polytechnics, Nigeria \\ ${ }^{2}$ Department of Biological Sciences, Federal University Gusau, Nigeria \\ ${ }^{3}$ Department of Microbiology, Yobe State University Damaturu, Nigeria \\ ${ }^{4}$ Department of Microbiology, Federal University Gusau, Nigeria
}

*Corresponding Author: Muhammad Ali, Department of Microbiology, Federal University Gusau, Nigeria, Email: alimuhd4real@gmail.com

\begin{abstract}
Dermatophytosis is a major public health problem in tropical and subtropical countries. The study was aimed to isolate and characterize some fungi associated with superficial fungal infections among secondary school student in Kano State Nigeria. A total of 38 (22 males and 16 females) subjects were involved in the study. A total 38 samples were collected from the subjects within Kano metropolis from April 2018 - October, 2018. Cotton swabs, soaked in $70 \%$ ethanol, were used to clean the infected area. Lesions were scrapped by a sterile scalpel and transported to laboratory for mycological examination. Direct microscopy using ten percent (10\%) of Potassium Hydroxide (KOH) was employed for microscopical examination. The samples were cultured on Sabouraud dextrose agar (SDA) for macroscopic evaluation. The results showed that a total of 68 fungi from 5 genera were isolated. Trichophyton spp was the most common fungal species isolated accounting for 30.9\%, followed by Microsporum spp 22\%, Aspergillus spp 19.1\%, Epidermophyton spp $16.2 \%$ and the least species is Candida spp 11.8\%. It is concluded both dermatophytes and non dermatophytes fungi were associated with superficial fungal infection.
\end{abstract}

Keywords: Dermatophytes, Dermatophytosis, fungi, Kano, prevalence

\section{INTRODUCTION}

Dermatophytosis (syn. ringworm, tinea) is a zoonotic disease caused by a group of fungi called dermatophytes. Dermatophytosis has a worldwide distribution. It is the most frequent mycotic infection in both humans and animals [1]. Epidermophyton, Microsporum and Trichophyton are the main genera of dermatophytes. Based on their ecology, they are classified into anthropophilic, geophilic and zoophilic. They can directly infect human through a contact with the infested animal or human and indirectly by acquiring the infective materials from the environment [2]. The infection mainly occurs in young camels less than three years [3]. Trichophyton and Microsporum genera are responsible for the majority of human infections causing more virulent disease when the infection are transmitted from animal to human than that transmitted from human to human [4]. Outbreaks of Trichophyton infection transmitted from cattle to humans are also reported [5].
Tinea capitis (ringworm of the scalp) is the most common fungal infection in children. More than $90 \%$ of the infections are caused by Trichophyton tonsurans, and fewer than 5\% are caused by Microsporum species [6].

Areas infected by dermatophytes may become secondarily infected by bacteria. Symptoms typically appear between 4 and 14 days following exposure [7]. The diagnosis of a dermatophytic infection is mostly done clinically, but often confused with other skin infections due to the topical application of steroid ointments and creams, leading to further misdiagnosis and mismanagement [8]. Hence, there arises the need for the correct, efficient, and rapid laboratory diagnosis of dermatophytes. The laboratory identification of dermatophytes is typically based on the macroscopic observation of colony morphology (pigmentation, growth rate, texture, etc.) grown on selective media, followed by a microscopic examination of conidia [9]. The Laboratory diagnosis of Dermatophytosis is carried out by 
different methods including, direct microscopic examination, culturing on Sabouraud dextrose agar (SDA) or other fungal media and by molecular identification using polymerase chain reactions (PCR). Direct microscopic examination is a simple and rapid method carried out on hairs and scales using KOH $20 \%$. It's a rapid method but has poor sensitivity (56\%) and may give false positive results especially if saprophytic fungal spores are present in the sample [10]. Fungal culture is carried out on Sabouraud dextrose agar or other specific culture media. Samples including hairs and scales should be collected from the margin of the lesions after gentile swabbing with ethyl alcohol $70 \%$ to reduce the risk of contamination. It is the gold standard for detection of dermatophytes and this method can determine the species [11].

The knowledge of social-demographic background of individuals infected with skin infections has not been the focus of most subSahara disease control programs impacting negatively to the well being of the individuals at risk [12]. Besides, most African countries have either scanty knowledge or have not identified the fungal species causing skin infections in their communities which is an essential component in management of this condition $[13,14]$ as well as in selection of therapy as treatment options may be altered based on the causative agent identified [12]. As result the study was aimed to isolate and characterize some fungi associated with superficial fungal infection among secondary school student in Kano State Nigeria.

\section{Materials AND Methods}

\subsection{Study Area}

Kano State is located in the North-Western Nigeria, it is located at latitude $11^{0} 3^{\prime} \mathrm{N}$ and longitude $8^{0} 3^{\prime} \mathrm{E}$. It share borders with Kaduna state to the south- west, Bauchi state to the South-East, Jigawa state to the East, Katsina state to the North. It has a total area of $20,131 \mathrm{~km} 2 \quad(7,777 \mathrm{sqm})$ and estimated population of 13.4 million [15]. Climate of the study areas have been described as 'AW' type as identified by Koppen's climatic classification [16]. The vegetation is a Savanna type simply described as closed grass or other predominantly herbaceous vegetation with scattered or widely spaced woody plants. Vegetation types in the state are the northern Guinea savanna and Sudan savanna. Northern Guinea Savanna is open woodland with grasses shorter than in the southern guinea where grasses are 1.5 to $3 \mathrm{~m}$ tall. The Sudan Savanna has scattered trees in open grassland with grasses under $1.2 \mathrm{~m}$ tall. The vegetation has been largely cleared for cultivation to form cultivated parkland. Parkland has scattered protected trees at some distance apart in open cultivated land [16].

\subsection{Sample Collection}

The study population consisted of 38 (22 males and 16 females) secondary school student aged between $12-20$ years with suspected superficial fungal infection. A total of 38 samples were collected from the subjects within Kano metropolis from April 2018 - October 2018. Cotton swabs, soaked in $70 \%$ ethanol, were used to clean the infected area. Lesions were scrapped by a sterile scalpel and collected in sterile disposable sterile Petri dishes and transferred to laboratory for mycological examination. Specimens were collected and sealed in sterile dry Petri dishes; they were labeled with the patient's name, age, sex, date of collection, and site of infection. The samples were divided into two portions: one for microscopic examination and one for culture.

\subsection{Direct Microscopical Examination}

On a clean glass slide, a part of each skin scrapings was placed. Ten percent $(10 \%)$ of Potassium Hydroxide (KOH) was used to digest the keratin material. The solution was then covered with a clean glass and gently heated for one minute. The slide was microscopically examined for fungal spores and hyphae under $10 \mathrm{X}$ and 40X magnifications [17].

\subsection{Isolation of Dermatophytes}

To isolate dermatophytes, skin scrapings were cultured on Sabouraud dextrose agar (SDA) containing chloramphenicol $(0.05 \mathrm{mg} / \mathrm{ml})$ and cyclohexamide $(0.5 \mathrm{mg} / \mathrm{ml})$. The inoculated plates were incubated at $27^{\circ} \mathrm{C}$ for up to six weeks. They were regularly observed for differentiated colonies. Growth rate, obverse, reverse pigmentation of the recovered colonies were reported [1].

\subsection{Identification of Dermatophytes}

Identification of dermatophytes was based on the colonies characteristic i.e macroscopically (color of the surface and reverse, topography, and texture) and microscopic features of the isolates. A small sample of each fungal mycelium free of the medium was examined using $10 \mathrm{X}$ and $40 \mathrm{X}$ objectives. The laboratory Handbook of Dermatophytes was used for fungal identification [18]. 


\section{RESULTS}

\subsection{Demographic Properties of the Subject}

A total of $22(57.9 \%)$ males and $16(42.1 \%)$ females took part in this study with ages ranging from less than 12 to over 20 years. Majority of the participants were 12 to 14 years age bracket.

Table1. Demographic Properties of the Subject

\begin{tabular}{|c|c|c|}
\hline Parameters & Frequency (n) & $\begin{array}{c}\text { Prevalence } \\
(\%)\end{array}$ \\
\hline \multicolumn{3}{|l|}{} \\
\hline Mex & 22 & 57.9 \\
\hline Female & 16 & 42.1 \\
\hline Age (years) & 16 & 42.1 \\
\hline $12-14$ & 12 & 31.6 \\
\hline $15-17$ & 10 & 26.3 \\
\hline $18-20$ &
\end{tabular}

\subsection{Macroscopic Identification of Fungi}

The macroscopic (morphological) and Microscopic examination of fungi isolated from 38 samples obtained from patients with suspected fungal skin infection is represented in Table 2. Colonial morphology of each isolate was recorded which was used to predict suspected organism. The result showed that a total of 5 different fungi were isolated.

Table2. Macroscopic and Microscopic Examination of fungi isolated from fungal skin infection

\begin{tabular}{|c|c|c|c|}
\hline \begin{tabular}{|l|} 
Isol. \\
Code \\
\end{tabular} & $\begin{array}{l}\text { Macroscopic } \\
\text { appearance }\end{array}$ & \begin{tabular}{|l|} 
Microscopic \\
appearance
\end{tabular} & \begin{tabular}{|l|} 
Organism \\
identified
\end{tabular} \\
\hline $\mathrm{I}_{1}$ & $\begin{array}{l}\text { White cottony } \\
\text { and circular } \\
\text { growth on } \\
\text { SDA plate }\end{array}$ & $\begin{array}{l}\text { Small and } \\
\text { cylindrical } \\
\text { shaped } \\
\text { macroconidia } \\
\text { occurring in } \\
\text { cluster }\end{array}$ & $\begin{array}{l}\text { Trichophyton } \\
\text { spp }\end{array}$ \\
\hline $\mathrm{I}_{2}$ & $\begin{array}{l}\text { Blue-black } \\
\text { mould on } \\
\text { SDA plates }\end{array}$ & $\begin{array}{l}\text { Conidiophores } \\
\text { terminate in a } \\
\text { ball like } \\
\text { structure }\end{array}$ & Aspergillus spp \\
\hline $\mathrm{I}_{3}$ & $\begin{array}{l}\text { White to } \\
\text { yellow downy } \\
\text { and powdery } \\
\text { colony on with } \\
\text { SDA plate } \\
\end{array}$ & $\begin{array}{l}\text { Spindle shape } \\
\text { micro conidia } \\
\text { terminal knob }\end{array}$ & $\begin{array}{l}\text { Microsporum } \\
\text { spp }\end{array}$ \\
\hline $\mathrm{I}_{4}$ & \begin{tabular}{|l|} 
Cream to \\
yellow colony \\
with smooth \\
and dry \\
texture
\end{tabular} & $\begin{array}{l}\text { Conidial } \\
\text { masses rises } \\
\text { hyphae } \\
\text { forming } \\
\text { grape-like } \\
\text { cluster along } \\
\text { the hyphae }\end{array}$ & Candida $\mathrm{spp}$ \\
\hline $\mathrm{I}_{5}$ & $\begin{array}{l}\text { Yellowish } \\
\text { green powdery } \\
\text { colony on } \\
\text { SDA plates }\end{array}$ & $\begin{array}{l}\text { Characterized } \\
\text { with club } \\
\text { shaped } \\
\text { macroconidia }\end{array}$ & $\begin{array}{l}\text { Epidermophyton } \\
\text { spp }\end{array}$ \\
\hline
\end{tabular}

\subsection{Prevalence of Fungal Isolates}

The prevalence of isolated fungi is presented in Table 3. A total of thirty eight (38) skin scrapings samples were collected from patients with suspected fungal skin infection and a total of 68 fungi from 5 genera were isolated. Trichophyton spp was the most common fungal species isolated accounting for $30.9 \%$, followed by Microsporum spp 22\%, Aspergillus spp $19.1 \%$, Epidermophyton spp $16.2 \%$ and the least species is Candida spp $11.8 \%$

Table3. Prevalence of fungal Isolates

\begin{tabular}{|c|c|c|}
\hline Fungi & Frequency (n) & Prevalence (\%) \\
\hline $\begin{array}{c}\text { Trichophyton } \\
\text { spp }\end{array}$ & 21 & 30.9 \\
\hline $\begin{array}{c}\text { Epidermophyton } \\
\text { spp }\end{array}$ & 11 & 16.2 \\
\hline Candida spp & 8 & 11.8 \\
\hline Aspergillus spp & 13 & 19.1 \\
\hline $\begin{array}{c}\text { Microsporum } \\
\text { spp }\end{array}$ & 15 & 22.0 \\
\hline Total & $\mathbf{6 8}$ & $\mathbf{1 0 0}$ \\
\hline
\end{tabular}

\section{DISCUSSION}

Dermatophytosis is a major public health problem in tropical and subtropical countries. From the result of the present study, the fungal agents responsible for skin infection included Trichophyton spp 30.9\%, Microsporum spp 22\%, Aspergillus spp 19.1\%, Epidermophyton spp $16.2 \%$ and Candida spp $11.8 \%$. This finding was in conformity with that of Nasreen [19] in Pakistan and that of Uthansingh [20] in India who both found the dermatophytes (Trichophyton, Microsporum and Epidermophyton) as the leading causes of fungal skin infection. On the other hand, this finding is contrary to that of Pierre [21] who found non dermatophytes as the leading cause of superficial fungal infection. The most dominant species in the present study is Trichophyton spp and this agrees with the report of Jha et al. [22] but contrary to that of Shalaby et al. [23] who reported Microsporum spp as the dominant species. These differences can be attributed to the fact that the prevalent fungal agents causing skin infection varies due to climate of the geographical region and may shift to another due to social demographic factors such as migration and health condition of individuals [24]. Presence of non dermatophytes such as Aspergillus spp in this study indicated its cosmopolitan distribution and known to cause superficial infections in immunocompromise individuals [25]. 
From the findings of the present study, there is high incidence of dermatophytosis among the suspected cases. This agrees with the findings of Shalaby et al. [23] who found higher incidence of dermatophytosis among children. High incidence among children aged between $10-20$ years may be attributed to increased physical activity and increased opportunity for exposure. As a school going student, there is increase in transmission between them due to increased contact, overcrowding in classrooms, lack of awareness and apathy to personal hygiene, sharing of personal items, and exposure to soil and even animals on playgrounds [23]. There is higher number of suspected cases and higher incidence of dermatophytosis among male than female in the present study. This supported the findings of Sumathi et al [26] and that of Shalaby et al. [23]. This is attributed to increased outdoor physical activities and increased sweating, which create a favorable environment for fungal infections, as well as a greater opportunity for exposure to infection in male than females.

\section{CONCLUSION}

Based on the findings of this study, dermatophytes fungal agents (Trichophyton, Microsporum and Epidermophyton) have shown to be the major cause of superficial fungal infection. However, non-dermatophytes such as Aspergillus and Candida were isolated. The fungal isolated are affecting more males than females according to this study. It is recommended that there is for proper mycological examination in the diagnosis of various dermatophytosis for their effective management.

\section{ACKNOWLEDGEMENT}

The authors wish to acknowledge to the technical staff of the department Science Laboratory Technology (SLT), Kano State Polytechnics for the use of Laboratory and provision of reagent. Thanks to the Ministry of Education and Health Kano State for the ethical approval.

\section{REFERENCES}

[1] Kane J, Summerbell R, Sigler L, Krajden S, and Land G (1997). Laboratory Handbook of Dermatophytes. Belmont, CA, USA: Star Publishing Company

[2] Hainer B. "Dermatophyte infections", A. F. P., vol. 67, pp. 101-108, 2003.
[3] Wisal AG and Salim MO (2010). Isolation and identification of dermatophytes from infected camels," Sudan J. Vet Res., vol. 25, pp. 94-53

[4] Kelly WR. (1984). Veterinary Clinical Diagnosis, 3rd ed. London: Bailliere and Tindal

[5] Ming PX, Ti YL, and Bulmer GM (2006). Outbreak of Trichophyton verrucosum in China transmitted from cows to humans, Mycopathologia, vol. 161, pp. 225-228

[6] Andrews MD, Burns M. (2008) Common Tinea Infections in Children. American Family Physician 77: 1415-1420.

[7] Yadav A, Urhekar AD, Mane V, Singh Danu M, Goel N, Ajit KG. (2013). Optimization and Isolation of Dermatophytes from Clinical Samples and In Vitro Antifungal Susceptibility Testing By Disc Diffusion Method. Journal of Microbiology and Biotechnology. 2(3): 19-34.

[8] Burzykowski T, Molenberghs G, Abeck D, Haneke E, Hay R, Katsambas A. (2003). High prevalence of foot diseases in Europe: results of the Achilles Project. Mycoses. 46(11-12): 496505. doi:10.1046/j.0933-7407.2003.00933.x. PMID: 14641624.

[9] Theel ES, Hall L, Mandrekar J, Wengenack NL. (2011). Dermatophyte identification using matrix-assisted laser desorption ionization-time of flight mass spectrometry. J Clin Microbiol. 49(12): 4067-71. doi: 10.1128/JCM.01280-11. PMID: 21956979, PMCID: PMC3232958.

[10] Sparkes A.H., Gruffydd-Johnes T.J., Shaw, S.E, Wright AI., Stokes CR. (1993). Epidemiological and diagnostic features of canine and feline dermatophytosis in United Kingdom from 1956 to 1991 . Vet. Rec. 133: 57-61

[11] Moriello KA and DeBoer DJ. (2012). Dermatophytosis in Greene CE (ed). Infectious Diseases of the dog and cat. 4th ed. St. Louis: Elsevier, pp 588-602.

[12] Chepchirchir A, Bii C. and Ndinya-achola J.O. (2009) Dermatophyte Infections in Primary School Children in Kibera Slums of Nairobi, East African Medical Journal vol. 86, Page: 5968.

[13] Ayaya SO, Kamar KK. and Kakai R. (2001) Aetiology of tinea capitis infection in school children, East Africa Medical Journal, Vol 78, Page: 531-535

[14] Kelly BP. (2012) Superficial Fungal infection, Pediatrics in Review, http://pedsinreview.aappublications.org/content /33/4/e22

[15] National Population Commission (NPC) (2014). National population census result Abuja, Nigeria

[16] Mohammed S, Muhammad NM, Abdulkarim IA (2015) Ethnobotanical Survey of Medicinal Plants in Metropolitan Kano, Nigeria 
International Journal of Public Health Research 3(6): 345-351.

[17] Larone D.H. (2011). Medically important fungi: A guide to identification, 5th ed. American Society for Microbiology. Washington, D.C.

[18] Hungerford LL, Campbell CL and Smith AR (1998). Veterinary Mycology Laboratory Manual. Ames.: Iowa State University Press

[19] Nasreen Khalid Thebo, Hidayatullah Abro, Abdul Qayoom soomro, Jawed Anwer and Muhammad Suhail (2006). Isolation and identification of dermatophytes from Sindh, Pakistan, Pak. J. Bot., Vol 38 (2): page 493495.

[20] Uthansingh K, Sahu MK, Debata NK, Behera D, Panda K, Sahu MC. (2019). Isolation and identification of fungus associated with skin and nail scalps of patients in a tertiary care teaching hospital. Apollo Med, 16:16-21

[21] Pierre Y, Christopher S, Namoomba SH, Lukwesa, Mwenya, Kwenda G, et al. (2016). Isolation and Identification of fungi from suspected fungal skin infections in patients attending the Dermatology Clinic at University Teaching Hospital IOSR Journal Of Pharmacy Volume 6, Issue 10, PP. 55-61
[22] Jha BK, Murthy SM, Devi NL. (2012). Molecular identification of dermatophytosis by polymerase chain reactionn(PCR) and detection of source of infection by restricted fragment length polymorphism (RFLP). Journal of College of Medical Sciences-Nepal. 8(4): 7-15. doi: 10.3126/jcmsn.v8i4.8694.

[23] Shalaby M.F.M, El-din A.N. and El-Hamd M.A. (2016). Isolation, Identification, and In Vitro Antifungal Susceptibility Testing of Dermatophytes from Clinical Samples at Sohag University Hospital in Egypt, Electronic Physician Volume: 8, Issue: 6, Pages: 25572567, DOI: http://dx.doi.org/10.19082/2557

[24] Woldeamanuel Y, Mengistu Y, Chryssanthou E, Petrini B. (2005). Dermatophytosis in Tulugudu Island, Ethiopia, Med Mycol,vol 43(1) page:79-82.

[25] Khalifa KA, Hadithi TS, Lami FH and Diwan JK. (2010) Prevalence of skin disorders among primary-school children in Baghdad governorate, Iraq, Eastern Mediterranean Health Journal, Vol. 16: page 209-213

[26] Sumathi S, Mariraj J, Shafiyabi S, Ramesh R, Krishna S. (2012). Clinicomycological study of dermatophytes. Int J Pharm Biomed Res. 4(2): 132-4.

Citation: Sani U. Diso, Ja'afar S. Adam, Lurwan Mu'azu, Muhammad S. Abdallah, Muhammad Ali. Isolation and Characterization of Some Fungi Associated with Superficial Fungal Infections. ARC Journal of Dermatology. 2020; 5(1):12-16. DOI: https://doi.org/10.20431/2456-0022.0501003.

Copyright: (C) 2020 Authors. This is an open-access article distributed under the terms of the Creative Commons Attribution License, which permits unrestricted use, distribution, and reproduction in any medium, provided the original author and source are credited. 